International Journal of Environmental Research and

Public Health

ISSN 1660-4601

www.mdpi.com/journal/ijerph

Article

\title{
Descriptive Analysis of Antibiotic-Resistant Patterns of Methicillin-Resistant Staphylococcus aureus (MRSA) st398 Isolated from Healthy Swine
}

\section{Ana Morcillo ${ }^{1}$, Beatriz Castro ${ }^{2}$, Cristobalina Rodríguez-Álvarez ${ }^{1}$, Rossana Abreu ${ }^{1}$, Armando Aguirre-Jaime ${ }^{3}$ and Angeles Arias ${ }^{1, *}$}

1 Department of Preventive Medicine and Public Health, University of La Laguna, Canary Islands 38071, Spain; E-Mails: anaimorcillo@gmail.com (A.M.); crrodrig@ull.es (C.R.-Á.); rabreu@ull.es (R.A.)

2 University Hospital of the Canary Islands, San Cristóbal de La Laguna, Tenerife, Canary Islands 38320, Spain; E-Mail: bcastrohdez@yahoo.es

3 Nuestra Señora de la Candelaria University Hospital, Santa Cruz de Tenerife 38010, Spain; E-Mail: aagujai@gobiernodecanarias.org

* Author to whom correspondence should be addressed; E-Mail: angarias@ull.es; Tel.: +34-922-319-379.

Academic Editor: Paul B. Tchounwou

Received: 5 November 2014 / Accepted: 4 January 2015 / Published: 12 January 2015

\begin{abstract}
Background: Livestock-associated methicillin-resistant Staphylococcus aureus (MRSA) such as the MRSA ST398 strain has spread all over the World and the most worrying aspect of this fact appears to be its capacity to easily spread to humans. The excessive use of antibiotics has made swine a reservoir of MRSA. The aim of the present study was to determine the antibiotic resistance profile of MRSA samples isolated from healthy swine of the island of Tenerife (Spain). Methods: A total of 256 MRSA isolates from swine samples and five MRSA isolates from pig worker samples were investigated for MRSA antibiotic resistant patterns. Results: Analysis of the susceptibility status of MRSA pig isolates revealed that 39 isolates were resistant to one antibiotic, 71 isolates were resistant to two antibiotics and 96 isolates were resistant to three or more antibiotics. SCCmec typing revealed the presence of types IV and V. Isolates having SCCmec IV had an increased resistance to the antimicrobial agents tested than those having SCCmec V. We observed significant differences when comparing the most common resistance patterns and SCCmec
\end{abstract}


type. Conclusions: MRSA isolated from humans showed similar resistance to those isolated from pigs, excepting erythromycin, since all the workers' isolates were sensitive to this antibiotic. The evolution of new MRSA clones has emphasized the need for infection control practices in animals and humans in close contact.

Keywords: MRSA; SCCmec; ST398; swine; antibiotic resistant

\section{Introduction}

Staphylococcus aureus is a common pathogen and a major public health concern associated with multiple diseases including skin and soft tissue infections, sepsis, osteomyelitis and pneumonia [1,2]. Methicillin-resistant Staphylococcus aureus (MRSA) epidemiology has drastically changed in recent years: at first it was a nosocomial pathogen (HA-MRSA) but now infections within the community are becoming more and more common amongst people with no contact with health centres (CO-MRSA). Since 2005, the presence of a distinct clone of MRSA has been reported in a wide variety of animal species and this has been referred to as livestock-associated MRSA (LA-MRSA) [3-6]. Most animals included in the food chain may be colonized with S. aureus. Recently, MRSA strains have been detected in food production animals, such as swine, cattle, chicken and other animals [7-10], as well as in various types of food products including raw chicken meat, retail pork and beef [11-13], milk and dairy products [14-19], and fishery products [20]. Previous studies have established that pigs are a reservoir for LAMRSA ST398 from which humans can be infected and ST398 is currently considered the most prevalent sequence type [21,22] although other molecular types have also been identified [23-25].

In Spain in 2008, the EFSA study found a prevalence of $46 \%$ MRSA in pigs and a prevalence of 46\% ST398 linage; non-ST398 MRSA were not detected [26].

The widespread use of antibiotics has led to the emergence of multidrug-resistant strains, making their eradication more difficult. Practices like preventive therapy (mainly of digestive and respiratory disorders), deviations from approved posology (prolonged treatment duration or under-dosing) are common in animal production facilities [27]. This use of antimicrobial drugs in food-producing animals is considered to contribute to the emergence of antimicrobial resistance [28,29]. In its latest report, the European Medicines Agency, 2014 [30], placed Spain as the third largest consumer of antibiotics (1693 tonnes, $21.2 \%$ of all antibiotics in the EU) for animal use in food producers.

Van Duijkeren et al. [31], found the number of colonized swine in farms applying oral group treatments, often with tetracycline, to be higher compared to farms with no such use of antimicrobials.

Smith et al. [32], reported that antibiotics in farms can trigger the emergence of resistant strains and those strains appear in meat, grocery stores and homes, and they can infect people. In $2009,80 \%$ of the antibiotics sold in the United States were used in farms [33]. Although contact with animals seems to be the most important risk factor for human ST398 carriage, meat products may also be a source [34]. In Europe, $46 \%$ of total meat consumption corresponds to pork [35] and possible transfer of resistant bacteria via pork meat seems to be inevitable. Therefore, control of antimicrobial resistance in swine should be a priority. 
The aim of the present study was to determine the antibiotic resistance profile of MRSA samples isolated from healthy swine and pig farm workers.

\section{Materials and Methods}

\subsection{Collection of Samples}

A cross-sectional prevalence study was conducted. A total of 300 pigs were screened: a randomized selection of 20 animals was taken from 15 wean-to-finishing farms for local consumption. The exploitation systems of swine livestock are of the intensive type, where animals are crammed into farms. The selected farms were those with $>250$ pigs. Nasal swab samples of healthy pigs, established under veterinarian supervision, from farms all over the island of Tenerife were collected at the Insular Slaughterhouse, between October 2009 and December 2010. Fifty-four nasal swabs of 54 pig workers were included in the study. These workers were from the same livestock farms and from the slaughterhouse [5]. Animals were transported by farm lorry to the Insular Slaughterhouse, where they were kept in separate stables according to their farm of origin and were slaughtered within $12 \mathrm{~h}$. Time of transportation was $1-2 \mathrm{~h}$.

\subsection{Isolation and Identification of Bacteria}

Samples were incubated in brain heart infusion (BHI) with $7 \% \mathrm{NaCl}$ for $18-24$ h at $37^{\circ} \mathrm{C}$. Then $10 \mu \mathrm{L}$ of the infusion was plated onto MRSA-ID culture plate (bioMérieux ${ }^{\circledR}$, Durham, NC, USA). MRSA colonies were preliminarily identified as characteristically green malachite coloured, round colonies. Isolates were confirmed as $S$. aureus by Gram stain appearance, catalase test and coagulase test agglutination Slidex Staph Plus (bioMérieux ${ }^{\circledR}$ ). Species identification was confirmed by Vitek ${ }^{\circledR} 2$ Automated Microbiology System with the ID card GP (bioMérieux ${ }^{\circledR}$ ). S. aureus ATCC 29213 was used as the reference strain. Methicillin resistance was confirmed by testing the presence of penicillin-binding-protein A (PBP2a) (MRSA-screen; Denka Seiken Co ${ }^{\text {TM }}$, Tokyo, Japan) and detecting the presence of the gene mecA by Real Time PCR (IQ ${ }^{\mathrm{TM}}$; Bio-Rad, Hercules, CA, USA) [5].

\subsection{Molecular Methods}

Molecular typing of MRSA was performed by ApaI Pulsed-field gel electrophoresis (PFGE) and Multilocus Sequence Typing (MLST). DNA from MRSA isolates was prepared in agarose blocks as described previously. Allelic profiles and sequence types were assigned according to the $S$. aureus MLST database (http://www.mlst.net). The different PFGE types and subtypes obtained were analyzed by SCCmec typing as described previously [5].

\subsection{Antimicrobial Susceptibility Testing}

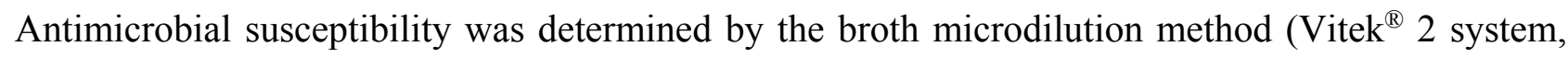
bioMérieux $^{\circledR}$ ) by using AST P588. S. aureus ATCC 29213 was used as reference strain. Strains were tested for susceptibility to aminoglucosides: gentamicin (GEN), tobramycin (TOB); betalactamic: bencylpenicillin (PG), oxacillin (OXA); glucopeptides: teicoplanin (TEI), vancomycin (VAN); quinolone: levofloxacin (LVX); lincosamides: clindamycin (CLI); Macrolides: erythromycin (ERY); 
rifamycin: rifampicin (RF); bacteriostatics trimethoprim-sulfametoxazole (SXT), fusidic acid (FUS); streptogramins: quinupristin-dalfopristin (SYN Q-D); oxazolidinone: linezolid (LNZ), glycylcycline: tigecicline (TGY); phosphate: fosfomycin (FOF); nitrofurane: nitrofurantoin (NIT); monoxycarbolic acid: mupirocine (MUPI). The breakpoints used were the same established by Clinical and Laboratory Standards Institute Guidelines [36]. Multidrug resistant bacteria were defined as bacteria that are resistant to four or more non- $\beta$ lactam antimicrobials. We compared the resistances to antibiotics, as well as the patterns of resistance according to SCCmec IV and SCCmec V found in the previous study [5].

\subsection{Statistical Analysis}

Categorical variables were compared with the chi-square test and Fisher's exact test. All analyses were performed using SPSS 21.00 for Windows (SPSS Inc., Chicago, IL, USA). A $p$-value $<0.05$ was considered statistically significant.

\section{Results}

\subsection{MRSA Pig Isolates}

Antimicrobial susceptibility panel testing was performed on 256 MRSA pig isolates. Resistance levels to antimicrobial for all isolates included: GEN ( $n=98,38.3 \%)$, TOB $(n=101,39.4 \%), \operatorname{LVX}(n=34$, $13.3 \%)$, ERY $(n=86,33.6 \%)$, CLI $(n=129,50.4 \%)$, NIT $(n=1,0.5 \%)$ and SXT $(n=99,38.7 \%)$.

Analysis of the susceptibility status of MRSA pig isolates revealed that $50(19.5 \%)$ isolates were susceptible to all antibiotics tested, except to betalactamic and 206 included a resistance to other antibiotics: $39(15.2 \%)$ isolates were resistant to one antibiotic, $71(27.7 \%)$ isolates were resistant to two antibiotics, 51 (19.9\%) isolates were resistant to three antibiotics and $45(17.5 \%)$ isolates were resistant to four or more non- $\beta$-lactam antibiotics. The remaining strains $(n=50)$ were susceptible to all antibiotics tested, except to $\beta$-lactam ones. SCCmec typing of our MRSA pig isolates revealed the presence of type IV and type V, and PFGE analysis found 12 different patterns, which all belonged to ST398. Isolates having SCCmec type IV had an increased resistance to the antimicrobial agents tested than those having SCCmec type V $(p<0.001)$. Only levofloxacin isolates with SCCmec type V presented a higher resistance. No significant differences were observed between type of SCCmec and erythromycin and clindamycin (Table 1).

Table 1. Statistical significance of antimicrobial resistance according to SCCmec type detected.

\begin{tabular}{lccc}
\hline \multirow{2}{*}{ Antimicrobial } & \multicolumn{2}{c}{ Number Resistant Isolates } & \multirow{2}{*}{ Significance(p) } \\
\cline { 2 - 3 } & SCCmec Type $\boldsymbol{I V}$ & SCCmec Type $\boldsymbol{~}$ & \\
\hline Gentamicin & 98 & 3 & $<0.001$ \\
Tobramycin & 98 & 5 & $<0.001$ \\
Trimethoprim-sulfomethoxazole & 88 & 9 & $<0.001$ \\
Levofloxacin & 0 & 21 & $<0.001$ \\
Erythromycin & 37 & 31 & Not significant \\
Clindamycin & 69 & 60 & Not significant \\
\hline
\end{tabular}


Nineteen different susceptibility patterns were obtained for all of the pig isolates of MRSA analyzed and many profiles were found in each farm. Over 37\% of the isolates showed multidrug resistance, $19.5 \%$ (50 strains) were susceptible to all tested antibiotics. The resistance profiles found in MRSA pig isolates and associated SCCmec types are shown in Table 2.

Table 2. Resistance patterns of MRSA isolates.

\begin{tabular}{lcccc}
\hline \multirow{2}{*}{ Resistance Pattern } & \multicolumn{3}{c}{ Pigs } & \multicolumn{2}{c}{ Humans } \\
\cline { 2 - 5 } & Number & Percentage (\%) & Number & Percentage (\%) \\
\hline PG + OXA & 50 & 19.5 & 2 & 40 \\
PG + OXA + ERY + CLI & 44 & 17.2 & - & - \\
PG + OXA + GEN + TOB + SXT & 41 & 16.0 & 1 & 20 \\
PG + OXA + GEN + TOB + ERY + CLI + SXT & 34 & 13.3 & - & - \\
PG + OXA + LVX + CLI & 19 & 7.4 & 1 & 20 \\
PG + OXA + LVX & 13 & 5.1 & - & - \\
PG + OXA + CLI & 13 & 5.1 & - & - \\
PG + OXA + SXT & 11 & 4.3 & - & - \\
PG + OXA + GEN + TOB & 8 & 3.1 & - & - \\
PG + OXA + GEN + TOB + CLI + SXT & 8 & 3.1 & 1 & - \\
PG + OXA + ERY + CLI + SXT & 3 & 1.2 & - & - \\
PG + OXA + GEN + TOB + CLI & 3 & 1.2 & - & - \\
PG + OXA + TOB + LVX + SXT & 2 & 0.8 & - & - \\
PG + OXA + GEN & 1 & 0.4 & - & - \\
PG + OXA + TOB & 1 & 0.4 & - & - \\
PG + OXA + GEN + TOB + ERY + CLI + FOS + SXT & 1 & 0.4 & - & - \\
PG + OXA + LVX + ERY + CLI & 1 & 0.4 & - & - \\
PG + OXA + GEN + TOB + ERY + CLI + NIT & 1 & 0.4 & - & - \\
PG + OXA + TOB + ERY + CLI & 1 & 0.4 & - & \\
PG + OXA + GEN + TOB + ERY + CLI & 1 & 0.4 & - & \\
\hline
\end{tabular}

We observed significant differences when comparing the most common resistance patterns of isolates and SCCmec type $(p<0.05)$. Patterns with PG + OXA + ERY + CLI resistance appear more frequently in those isolates having SCCmec type V. On the other hand, patterns with $\mathrm{PG}+\mathrm{OXA}+\mathrm{GEN}+\mathrm{TOB}+$ SXT resistance and PG + OXA + GEN + TOB + ERY + CLI + SXT resistance are more common in isolates with SCCmec type IV. Multidrug resistance was found in $37 \%$ of the tested strains. Benzylpenicillin (PG); oxacillin (OXA); levofloxacin (LVX); clindamycin (CLI); erythromycin (ERY); trimethoprim-sulfomethoxazole (SXT); fosfomycin (FOF); nitrofurantoin (NIT); gentamicin (GEN); tobramycin (TOB).

\subsection{MRSA Human Isolates}

Antimicrobial susceptibility panel testing was performed on 5 MRSA workers' isolates and 4 different antimicrobial resistance patterns were obtained: $\mathrm{PG}+\mathrm{OXA}$; PG + OXA + GEN + TOB + SXT; $\mathrm{PG}+\mathrm{OXA}+\mathrm{LVX}+\mathrm{CLI}$ and $\mathrm{PG}+\mathrm{OXA}+\mathrm{GEN}+\mathrm{TOB}+\mathrm{CLI}+\mathrm{SXT}$. We observed that the antimicrobial susceptibility obtained was similar to those obtained in pig isolates excepting erythromycin, since all the workers' isolates were sensitive to this antibiotic. MRSA strains were 
SCCmec type IV or V, coinciding with those found in pigs, though in the workers SCCmec type IV was the majority, while in pigs it was SCCmec type V.

\section{Discussion}

\subsection{MRSA Pig Isolates}

The problem of the emergence of resistant microorganisms such as MRSA associated with livestock is closely related to the inadequate use of antimicrobial agents in veterinary care $[9,37]$ and international trade of food of animal origin can facilitate the spread of resistant strains. Antibiotics have long been used for treating disease, preventing disease, and improving feed efficiency in conventional livestock and poultry production. Concerns over the spread of antibiotic-resistant genes to human and animal pathogens continue to drive the debate. Alternatives to antibiotics in food-producing animals, such as pre- and probiotics or vaccines, are considered necessary [38]. Intensive livestock productions, where animals are in crowded conditions, are more numerous than expansive livestock productions, where animals are at liberty. Intensive livestock system favours the spread of resistant strains.

In a study performed by van Duijkeren et al. [31] it was demonstrated that the number of swine colonized by MRSA was high in farms that were applying intensive oral treatments, compared with those farms that were not doing it. Nevertheless, in another study conducted by Broens et al. [39] they did not find such association. Preventive therapy or the treatment of healthy animals that coexist with unhealthy ones, the use of subdosis or treatments of excessive duration in time can represent a risk factor for the appearance of these strains. As a limitation of this study, we emphasize that in all cases the animals in our study came from intensive production farms, but we did not have access to any information related to their use of antimicrobials.

There are several studies related to the antibiotic susceptibility in MRSA isolated from swine. In our study we obtained a high percentage of resistance to clindamycin (50.4\%), tobramycin (39.4\%) and gentamycin (38.3\%). We also want to highlight the resistance values obtained for trimethoprim-sulfamethoxazole (38.7\%) and erythromycin (3.6\%). As in other studies, our most represented multi-resistant pattern was the one that included PG + OXA + GEN + TOB + ERY + CLI + SXT, appearing in $13.3 \%$ of the cases $[9,10,24,25,40,41]$. Another important pattern of resistance detected was the combined resistance to erythromycin and clindamycin (17\%), a percentage that in our study was lower than in the study of Neeling et al. [9], 23\%. In the same study they found that $36 \%$ of the strains were resistant to kanamycin, gentamycin and tobramycin, a percentage similar to the one we obtained.

We obtained a high percentage of resistance to trimethoprim-sulfamethoxazole (38.7\%), although lower than the $52 \%$ obtained by van Duijkeren et al. [31], who affirmed that the pressure of the antimicrobial selection is one of the probable factors that have facilitated the emergence and dispersion of the veterinary MRSA, the most commonly used being tetracycline and trimethoprim-sulfamethoxazole and to which these microorganisms are more resistant. Furthermore, in another Dutch study, Van den Broek et al. [37] found that 52\% of MRSA were resistant to trimethoprim-sulfamethoxazole, erythromycin and clindamycin. Smith et al. [42], in a study of antibiotic susceptibility in MRSA, found that all isolates were susceptible to the majority of the antibiotics tested (trimethoprim-sulfamethoxazole, levofloxacin, vancomycin, aminoglucoside, etc.). 
Nevertheless, as previously mentioned, we found a significant percentage of strains resistant to trimethoprim-sulfamethoxazole, aminoglucoside and levofloxacin. These authors gave lower erythromycin resistance rates than ours $(20 \%)$, but they found a $87 \%$ resistance to clindamycin. Battisti et al. [24] obtained higher rates of resistance than ours to trimethoprim-sulfamethoxazole, (68.8\%) and erythromycin (60.9\%). In the study performed by Osadebe et al. [43], 83\% of MRSA isolates were resistant to erythromycin, $50 \%$ had intermediate resistance to doxycycline and $25 \%$ to ciprofloxacin, while all strains were susceptible to linezolid, rifampycin, vancomycin, and trimethoprim-sulfamethoxazole.

All the MRSA strains of the study were ST398 and contained the SCCmec that codifies gene mecA. When we compared SCCmec type IV and V, defined as different short cassettes, with the antibiotic resistance for epidemiological interest, significant differences were observed for gentamycin, tobramycin, levofloxacin and trimethoprim-sulfamethoxazole. MRSA isolates having SCCmec type IV had higher resistance rates to gentamycin, tobramycin and trimethoprim-sulfamethoxazole than those with SCCmec type V $(p<0.005)$. Nevertheless, in the case of levofloxacin the resistance was predominant in the strains with SCCmec type V ( $p=0.005)$. In the study conducted by Gómez-Sanz et al. [25], they observed that the strains with SCCmec type IV presented a higher resistance to gentamycin and tobramycin than those having SCCmec type V. We observed the same association. In our study we also observed that the resistance pattern that includes more antibiotics corresponded to those MRSA isolates having SCCmec type IV and this difference was significant $(p=0.005)$. Gómez-Sanz et al. [25], also indicated that the genotype of multi-resistance is generally associated with the presence of SCCmec type IV. In this way we found that resistance pattern PG + OXA + ERY + CLI appeared more frequently in the strains having SCCmec type V $(p=0.005)$ and patterns $\mathrm{PG}+\mathrm{OXA}+\mathrm{GEN}+\mathrm{TOB}+\mathrm{SXT}$ and $\mathrm{PG}+\mathrm{OXA}+\mathrm{GEN}+$ $\mathrm{TOB}+\mathrm{ERY}+\mathrm{CLI}+\mathrm{SXT}$ in those having SCCmec type IV and these differences were significant $(p=0.005)$. Abreu et al. [44] carried out a study on detection of MRSA in black Canarian pigs on the island of Tenerife (Spain); this is an autochthonous porcine race considered to be a descendant from the Mediterranean pig, and also found a high prevalence of colonization (62\%), concretely with the ST-398 strain. Resistance pattern PG + OXA + GEN + CLI + SXT was observed in the majority of isolates. [44]. Moreover, another study performed in Spain by Porrero et al. [45], comparing carriage of MRSA in Iberian pigs (IP) and Standard white pigs (SWP) found low prevalence and higher susceptibility to antibiotics in IP. The resistance pattern to gentamicin, ciprofloxacin and erythromycin was higher in SWP than in IP.

\subsection{MRSA Human Isolates}

MRSA ST398 has been described as a cause of infections in people occupationally exposed to pigs, by direct or indirect contact and occasionally can be introduced into hospitals as a result of community-acquired human infections. Although it may become part of the endemic flora of the slaughterhouse, the risk of infection to slaughterhouse workers and people handling meat appears to be low. In most cases, colonization with MRSA ST398 in humans is not associated with disease, although clinical cases associated with MRSA ST398 have been reported. MRSA ST398 can be introduced into hospitals via colonized farmers and other people in a region with intensive pig farming. However, 
it seems that the capacity for dissemination in humans (patient-to-patient transmission) of livestock-origin MRSA is lower as compared to hospital-associated MRSA [26].

Different studies have demonstrated the correlation between the nasal colonization by MRSA with the frequency of contact with pigs apart from the high presence of MRSA strains in farms; many reports comment the colonization of farm workers with ST398 [7,22,46]. The prevalence of MRSA found in our study was less than that found in other countries [21,22,32]. A limitation of the study was the small number of isolates in workers that could not perform the statistical analysis of susceptibility patterns of MRSA isolated from pig and workers' samples.

In relation to resistance patterns, there are some studies such as Wulf et al. [22] who isolated MRSA from 34 veterinarians from a total of 272 attending a convention in the Netherlands; after antibiotic sensitivity tests, $58 \%$ of the isolates were resistant to five or more types of antibiotics. They associated these results to antibiotic consumption by livestock. They found strains highly resistant to tetracycline (70\%), trimethoprim-sulfamethoxazole (SXT $(48 \%)$ and gentamicin $(20 \%)$. They also showed that 4/31 resistant to ciprofloxacin isolates corresponded to two veterinarians from Italy and two veterinarians from Spain. Smith et al. [42] indicated that none of the 9 ST398 MRSA isolates from humans were resistant to erythromycin or quinupristin-dalfopristin, but one of them (11\%) was resistant to clindamycin. The susceptibility patterns obtained in this study were PG + OXA + GEN + TOB + CLI $+\mathrm{SXT}, \mathrm{PG}+\mathrm{OXA}+\mathrm{GEN}+\mathrm{TOB}+\mathrm{SXT}$ and PG + OXA + CLI + LVX (Table 2); the other two isolates were resistant only to $\beta$-lactams. Van den Broek et al. [37] obtained higher rates of antimicrobial resistance than in our study. He compared the prevalence of MRSA in population with and without pig contact, indicating that all MRSA ST398 isolates in humans showed a high resistance to trimethoprim-sulfamethoxazole (SXT), erythromycin and clindamycin (52\%).

\section{Conclusions}

The findings from this study support some of the results from other studies. All MRSA strains were isolated from healthy swine and it should be noted that $37 \%$ of the isolates were multidrug resistant, considering that major control program of the use of antibiotics in veterinary care is necessary in order to detect any expansion or increase of new antibiotic resistance as this could be a public health problem because of their possible transmission to the community. Systematic surveillance and monitoring of MRSA in humans and food producing animals is recommended.

\section{Author Contributions}

Ana Morcillo, Beatriz Castro, Cristobalina Rodríguez-Álvarez, Rossana Abreu, Armando Aguirre-Jaime and Angeles Arias conceived and designed the experiments; Ana Morcillo, Beatriz Castro, and Rossana Abreu performed the experiments; Cristobalina Rodríguez-Álvarez, Armando Aguirre-Jaime, and Angeles Arias analyzed the data; Ana Morcillo, Beatriz Castro, Cristobalina Rodríguez-Álvarez, Rossana Abreu and Angeles Arias wrote the paper.

\section{Conflicts of Interest}

The authors declare no conflict of interest. 


\section{References}

1. Kechrid, A.; Pérez-Vázquez, M.; Smaoui, H.; Hariga, D.; Rodríguez-Baños, M.; Vindel, A.; Baquero, F.; Cantón, R.; del Campo, R. Molecular analysis of community-acquired methicillin-susceptible and resistant Staphylococcus aureus isolates recovered from bacteraemic and osteomyelitis infections in children from Tunisia. Clin. Microbiol. Infect. 2011, 17, 1020-1026.

2. Talan, D.A.; Krishnadasan, A.; Gorwitz, R.J.; Fosheim, G.E.; Limbago, B.; Albrecht, V.; Moran, G.J. Emergency ID Net Study Group. Comparison of Staphylococcus aureus from skin and soft-tissue infections in U.S. emergency department patients, 2004 and 2008. Clin. Infect. Dis. 2011, 53, 144-149.

3. Graveland, H.; Wagenaar, J.A.; Heesterbeek, H.; Mevius, D.; van Duijkeren, E.; Heederik, D. Methicillin resistant Staphylococcus aureus ST398 in veal calf farming, human MRSA carriage related with animal antimicrobial usage and farm hygiene. PLoS One 2010, 5, doi:10.1371/journal.pone.0010990.

4. Ferber, D. Infectious disease. From pigs to people, the emergence of a new superbug. Science 2010, 27, 1010-1011.

5. Morcillo, A.; Castro, B.; Rodríguez-Álvarez, C.; González, J.C.; Sierra, A.; Montesinos, M.I.; Abreu, R.; Arias, Á. Prevalence and characteristics of methicillin-resistant Staphylococcus aureus in pigs and pig workers in Tenerife, Spain. Foodborne Pathog. Dis. 2012, 9, 207-210.

6. Verhegghe, M.; Pletinckx, L.J.; Crombé, F.; Vandersmissen, T.; Haesebrouck, F.; Butaye, P.; Heyndrickx, M.; Rasschaert, G. Methicillin-resistant Staphylococcus aureus (MRSA) ST398 in pig farms and multispecies farms. Zoonoses Public Health 2013, 60, 366-374.

7. Huijsdens, X.W.; van Dijke, B.J.; Spalburg, E.; van Santen-Verheuvel, M.G.; EOC Heck, M.; Pluister, G.N.; Voss, A.; Wannet, W.J.B.; de Neeling, A.J. Community-acquired MRSA and swine-farming. Ann. Clin. Microbiol. Antimicrob. 2006, 5, doi:10.1186/1476-0711-5-26.

8. Lee, J.H. Occurrence of methicillin-resistant Staphylococcus aureus strains from cattle and chicken, and analyses of their mecA, mecRl and mecI genes. Vet. Microbiol. 2006, 16, 155-159.

9. De Neeling, A.J.; van den Broek, M.J.; Spalburg, E.C.; van Santen-Verheuvel, M.G.; Dam-Deisz, W.D. High prevalence of methicillin resistant Staphylococcus aureus in swines. Vet. Microbiol. 2007, 122, 366-372.

10. Mulders, M.N.; Haenen, A.P.; Geenen, P.L.; Vesseur, P.C.; Poldervaart, E.S.; Bosch, T.; Huijsdens, X.W.; Hengeveld, P.D.; Dam-Deisz, W.D.; et al. Prevalence of livestock-associated MRSA in broiler flocks and risk factors for slaughterhouse personnel in The Netherlands. Epidemiol. Infect. 2010, 138, 743-755.

11. Kitai, S.; Shimizu, A.; Kawano, J.; Sato, E.; Nakano, C.; Uji, T.; Kitagawa, H. Characterization of methicillin-resistant Staphylococcus aureus isolated from retail raw chicken meat in Japan. J. Vet. Med. Sci. 2005, 67, 107-110.

12. Kwon, N.H.; Park, K.T.; Jung, W.K.; Youn, H.Y.; Lee, Y.; Kim, S.H.; Bae, W.; Lim, J.Y.; Kim, J.Y.; Kim, J.M.; Hong, S.K.; Park, Y.H. Characteristics of methicillin resistant Staphylococcus aureus isolated from chicken meat and hospitalized dogs in Korea and their epidemiological relatedness. Vet. Microbiol. 2006, 31, 304-312. 
13. Normanno, G.; Corrente, M.; la Salandra, G.; Dambrosio, A.; Quaglia, N.C.; Parisi, A.; Greco, G.; Bellacicco, A.L.; Virgilio, S.; Celano, G.V. Methicillin-resistant Staphylococcus aureus (MRSA) in foods of animal origin product in Italy. Int. J. Food Microbiol. 2007, 30, 117, 219-222.

14. Gundogan, N.; Citak, S.; Yucel, N.; Devren, A. A note on the incidence and antibiotic resistance of Staphylococcus aureus I solated from meat and chicken samples. Meat Sci. 2005, 69, 807-810.

15. Peles, F.; Wagner, M.; Varga, L.; Hein, I.; Rieck, P.; Gutser, K.; Keresztúri, P.; Kardos, G.; Turcsányi, I.; Béri, B.; Szabó, A. Characterization of Staphylococcus aureus strains isolated from bovine milk in Hungary. Int. J. Food Microbiol. 2007, 118, 186-193.

16. Pereira, V.; Lopes, C.; Castro, A.; Silva, J.; Gibbs, P.; Teixeira, P. Characterization for enterotoxin production, virulence factors, and antibiotic susceptibility of Staphylococcus aureus isolates from various foods in Portugal. Food Microbiol. 2009, 26, 278-282.

17. Fessler, A.T.; OldeRiekerink, R.G.; Rothkamp, A.; Kadlec, K.; Sampimon, O.C.; Lam, T.J.; Schwarz, S. Characterization of methicillin-resistant Staphylococcus aureus CC398 obtained from humans and animals on dairy farms. Vet. Microbiol. 2012, 9, 77-84.

18. Lim, S.K.; Nam, H.M.; Jang, G.C.; Lee, H.S.; Jung, S.C.; Kim, T.S. Transmission and persistence of methicillin-resistant Staphylococcus aureus in milk, environment, and workers in dairy cattle farms. Foodborne Pathog. Dis. 2013, 10, 731-736.

19. Kreausukon, K.; Fetsch, A.; Kraushaar, B.; Alt, K.; Müller, K.; Krömker, V.; Zessin, K.H.; Käsbohrer, A.; Tenhagen, B.A. Prevalence, antimicrobial resistance, and molecular characterization of methicillin-resistant Staphylococcus aureus from bulk tank milk of dairy herds. J. Dairy Sci. 2012, 95, 4382-4388.

20. Rhee, C.H.; Woo, G.J. Emergence and characterization of foodborne methicillin-resistant Staphylococcus aureus in Korea. J. Food Prot. 2010, 73, 2285-2290.

21. Voss, A.; Loeffen, F.; Bakker, J.; Klaassen, C.; Wulf, M. Methicillin-resistant Staphylococcus aureus in swine farming. Emerging Infect. Dis. 2005, 11, 1965-1966.

22. Wulf, M.W.; Sørum, M.; van Nes, A.; Skov, R.; Melchers, W.J.; Klaassen, C.H.; Voss, A. Prevalence of methicillin-resistant Staphylococcus aureus among veterinarians, an international study. Clin. Microbiol. Infect. 2008, 14, 29-34.

23. Wagenaar, J.A. Lifestock associated MRSA, epidemiology in animal production, transmission to humans and characterization of the strain. Tijdschr. Diergeneeskd. 2009, 134, 1032-1035.

24. Battisti, A.; Franco, A.; Merialdi, G.; Hasman, H.; Iurescia, M.; Lorenzetti, R.; Feltrin, F.; Zini, M.; Aarestrup, F.M. Heterogeneity among methicillin-resistant Staphylococcus aureus from Italian swine finishing holdings. Vet. Microbiol. 2010, 142, 361-366.

25. Gómez-Sanz, E.; Torres, C.; Lozano, C.; Fernández-Pérez, R.; Aspiroz, C.; Ruiz-Larrea, F.; Zarazaga, M. Detection, molecular characterization, and clonal diversity of methicillin-resistant Staphylococcus aureus CC398 and CC97 in Spanish slaughter swines of different age groups. Foodborne Pathog. Dis. 2010, 7, 1269-1277.

26. European Food Safety Authority (EFSA). Analysis of the Baseline Survey on the Prevalence of Methicillin-Resistant Staphylococcus aureus (MRSA) in Holdings with Breeding Pigs, in the EU, 2008, Part A: MRSA Prevalence Estimates; on Request from the European Commission. Available online: http://www.efsa.europa.eu/en/efsajournal/doc/1376.pdf (accessed on 6 January 2015). 
27. Timmerman, T.; Dewulf, J.; Catry, B.; Feyen, B.; Opsomer, G.; de Kruif, A.; Maes, D. Quantification and evaluation of antimicrobial drug use in group treatments for fattening pigs in Belgium. Prev. Vet. Med. 2006, 74, 251-263.

28. Aarestrup, F.M. Association between the consumption of antimicrobial agents in animal husbandry and the occurrence of resistant bacteria among food animals. Int. J. Antimicrob. Agents 1999, 12, 279-285.

29. Gyssens, I.C. Quality measures of antimicrobial drug use. Int. J. Antimicrob. Agents 2001, 17, 9-19.

30. Van Duijkeren, E.; Ikawaty, R.; Broekhuizen-Stins, M.J.; Jansen, M.D.; Spalburg, E.C.; de Neeling, A.J.; Allaart, J.G.; van Nes, A.; Wagenaar, J.A.; Fluit, A.C. Transmission of methicillin-resistant Staphylococcus aureus strains between different kinds of pig farms. Vet. Microbiol. 2008, 126, 383-389.

31. European Medicines Agency (EMA). European Surveillance of Veterinary Antimicrobial Consumption, 2014. "Sales of Veterinary Antimicrobial Agents in 26 EU/EEA Countries in 2012” (EMA/333921/2014). Available online: http://www.ema.europa.eu/docs/en_GB/ document_library/Report/2014/10/WC500175671.pdf (accessed on 15 October 2014).

32. Smith, T.C.; Male, M.J.; Harper, A.L.; Kroeger, J.S.; Tinkler, G.P.; Moritz, E.D.; Capuano, A.W.; Herwaldt, L.A.; Diekema, D.J. Methicillin-resistant Staphylococcus aureus (MRSA) strain ST398 is present in midwestern U.S. swine and swine workers. PLoS One 2009, 4, doi:10.1371/journal.pone.0004258.

33. Mole, B. MRSA, Farming up trouble. Nature 2013, 499, 398-400.

34. Van Duijkeren, E.; Jansen, M.D.; Flemming, S.C.; de Neeling, H.; Wagenaar, J.A.; Schoormans, A.H.; van Nes, A.; Fluit, A.C. Methicillin-resistant Staphylococcus aureus in pigs with exudative epidermitis. Emerg. Infect. Dis. 2007, 13, 1408-1410.

35. EUROSTAT 2003. Available online: http//epp.eurostat.ec.europa.eu/ (accessed on 2 October 2014).

36. Clinical Laboratory Standards Institute (2011). Available online: http://www.clsi.org/ (accessed on 26 January 2010).

37. Van den Broek, I.V.; van Cleef, B.A.; Haenen, A.; Broens, E.M.; van der Wolf, P.J.; van Den Broek, M.J.; Huijsdens, X.W.; Kluytmans, J.A.; van de Giessen, A.W.; Tiemersma, E.W. Methicillin-resistant Staphylococcus aureus in people living and working in pig farms. Epidemiol. Infect. 2009, 137, 700-708.

38. Broens, E.M.; Graat, E.A.; van Der Wolf, P.J.; van de Giessen, A.W.; de Jong, M.C. Transmission of methicillin resistant Staphylococcus aureus among swine during transportation from farm to abattoir. Vet. J. 2010, 147, 440-444.

39. Allen, H.K.; Levine, U.Y.; Looft, T.; Bandrick, M.; Casey, T.A. Treatment, promotion, commotion: Antibiotic alternatives in food-producing animals. Trends Microbiol. 2013, 21, 114-119. doi:10.1016/j.tim.2012.11.001.

40. Witte, W.; Strommenger, B.; Stanek, C.; Cuny, C. Methicillin-resistant Staphylococcus aureus ST398 in humans and animals, Central Europe. Emerg. Infect. Dis. 2007, 13, 255-258.

41. Kadlec, K.; Ehricht, R.; Monecke, S.; Steinacker, U.; Kaspar, H.; Mankertz, J.; Schwarz, S. Diversity of antimicrobial resistance pheno- and genotypes of methicillin-resistant Staphylococcus aureus ST398 from diseased swine. J. Antimicrob. Chemother. 2009, 64, 1156-1164. 
42. Smith, T.C.; Gebreyes, W.A.; Abley, M.J.; Harper, A.L.; Forshey, B.M.; Male, M.J.; Martin, H.W.; Molla, B.Z.; Sreevatsan, S.; Thakur, S.; et al. Methicillin-resistant Staphylococcus aureus in swines and farm workers on conventional and antibiotic-free swine farms in the USA. PLoS One 2013, 7 , doi:10.1371/journal.pone.0063704.

43. Osadebe, L.U.; Hanson, B.; Smith, T.C.; Heimer, R. Prevalence and characteristics of Staphylococcus aureus in Connecticut swine and swine farmers. Zoonoses Public Health 2013, 60, 234-243.

44. Abreu, R.; Morcillo, A.; González, J.C.; Castro, B.; Pérez-Dorado, F.; Álvarez-Marante, R.; Rodríguez-Álvarez, C.; Arias, A. Staphylococcus aureus resistente a meticilina aislados de cerdo negro canario. Hig. Sanid. Ambient. 2011, 11, 752-758.

45. Porrero, M.C.; Wassenaar, T.M.; Gómez-Barrero, S.; García, M.; Bárcena, C.; Álvarez, J.; Sáez-Llorente, J.L.; Fernández-Garayzábal, J.F.; Moreno, M.A.; Domínguez, L. Detection of methicillin-resistant Staphylococcus aureus in Iberian pigs. Lett. Appl. Microbiol. 2012, 54, 280-285.

46. Dahms, C.; Hübner, N.O.; Cuny, C.; Kramer, A. Occurrence of methicillin-resistant Staphylococcus aureus in farm workers and livestock enviroment in Mecklenburg-Western Pomerania, Germany. Acta Vet. Scand. 2014, 56, doi:10.1186/s13028-014-0053-3.

(C) 2015 by the authors; licensee MDPI, Basel, Switzerland. This article is an open access article distributed under the terms and conditions of the Creative Commons Attribution license (http://creativecommons.org/licenses/by/4.0/). 